\title{
Determination of the parameters of the synchronous motor with dual excitation
}

\author{
Moez Hadj Kacem ${ }^{1}$, Souhir Tounsi ${ }^{2}$, Rafik Neji ${ }^{1}$ \\ ${ }^{1}$ Electrical Engineering Department, National School of Engineers of Sfax , Sfax University, Sfax, Tunisia \\ ${ }^{2}$ Industrial Informatic Department, National School of Electronics and Telecommunications of Sfax, Sfax University, Sfax, Tunisia
}

\section{Email address:}

Moez_haj_kacem@voila.fr (Moez H. K.), souhir.tounsi@isecs.rnu.tn (Souhir T.), rafik.neji@enis.rnu.tn (Rafik N.)

\section{To cite this article:}

Moez Hadj Kacem, Souhir Tounsi, Rafik Neji. Determination of the Parameters of the Synchronous Motor with Dual Excitation. American Journal of Electrical Power and Energy Systems. Special Issue: Design, Optimization and Control of Electric Vehicles: (DOCEV). Vol. 4, No. 2-1, 2015, pp. 26-32. doi: 10.11648/j.epes.s.2015040201.14

\begin{abstract}
This paper describes the electric parameters determination for Synchronous Motor with Dual Excitation, using the joined method analytic/finite elements. Indeed several models of mutual and principal inductances and electric motor constant are developed analytically and validated by the finite elements method. These models are fortunately parameterized allowing to the formulation of several optimization problems such as the motor ripple torque.
\end{abstract}

Keywords: Synchronous Motor, Dual Excitation, Electric Vehicles, Torque

\section{Introduction}

For electric traction applications, synchronous or asynchronous motors [1] with radial or axial fluxes [2, 3], can be used. In order to increase the torque generation capability, these motors can be modulated. Moreover, the consequent progress of the permanent-magnet technology makes permanent magnets synchronous motors more and more utilized for variable speed and high performance systems.

At the same time, in a context where public opinion is in caressingly sensitive to the problems of pollution and the depletion of fossil fuels (oil, gas, etc ....), a growing number of industrial organizations and public or private researches trying to find innovative technological solutions for better energy management. Machines double excitation (MSDE) fully meet requirements more stringent. Indeed, it appears that the authors' concept of double excitation offers the possibility of obtaining innovative and efficient electric machines.

The principle of double excitation [2] is to associate in electrical machines synchronous permanent magnet excitation and an excitation coil allowing operational flexibility and a good design of the converter assembly machine.

Possible applications of this type of machine are many and varied. The MSDE can be used in the production of electrical energy which they function as generators. But their application is preferred especially in the field of electric or hybrid drive.

\section{Generalities about Synchronous Motor with Dual Excitation}

The excitation flux is created by two different sources, one is permanent magnet, another wound (in most cases) [4] or permanent magnets (the mechanical weakening) [5], the aim being to use the second excitation source to control the flow in the gap

Depending on how the two circuits are arranged excitement there are several types of machines with double excitation. We have classified into two categories:

- double excitation synchronous parallel machines

- double excitation synchronous series machines

\subsection{Parallel Excitation Synchronous Motor}

The double excitation parallel offers many opportunities arrangement of the two excitation circuits. A varied panorama of solutions exists in the literature [4,-9], the following is an example for illustration.

We can see the diagram of a double parallel excitation in 
Figure 1 [2-9]. For this type of excitation, the permanent magnets and the coil are at the rotor.
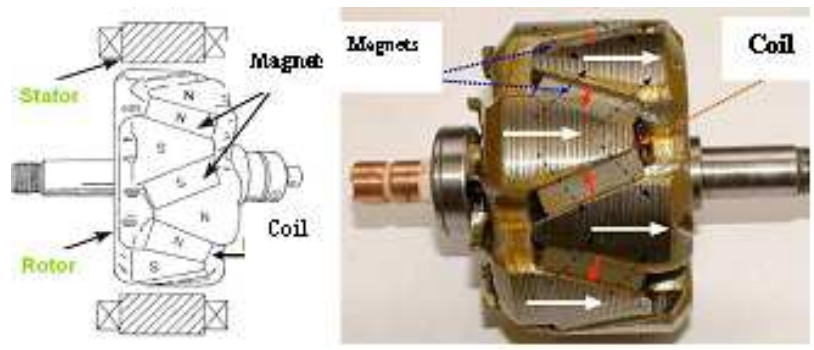

Figure 1. Synchrones machine with parallel double excitation.

This machine is more like a wound rotor machine, on which would add magnets to improve performance, to a machine magnet which we want to control the flow. In terms of

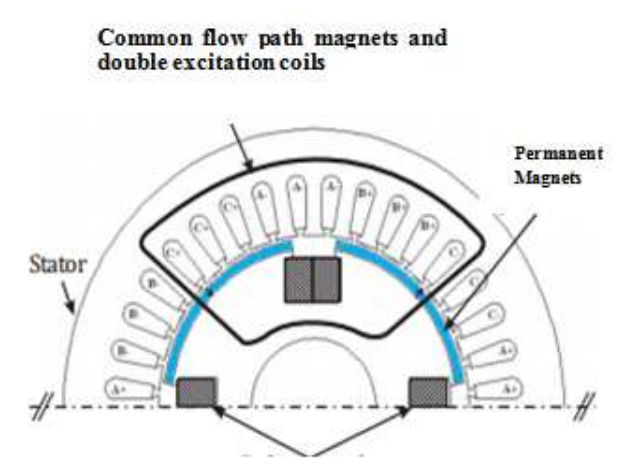

Double excitation coils performance, it is not certain that this solution can compete with magnet machines.

\subsection{Serial Double Excitation Synchronous Machine}

The schematic diagram of this type of double excitation is given in figure 2 [5]. For this type of double excitation, the flow through the excitation coil magnets. The flow of excitation coil and the magnets on the same path. Reducing the flow in the gap is carried out by injecting into the coils a current which creates a DMF opposite to that of the magnets. The power of the coil current is bidirectional, which increases the cost of food and therefore the overall cost. An iron loss for this type of machine down, this is one of the additional benefits specific to this structure [7].

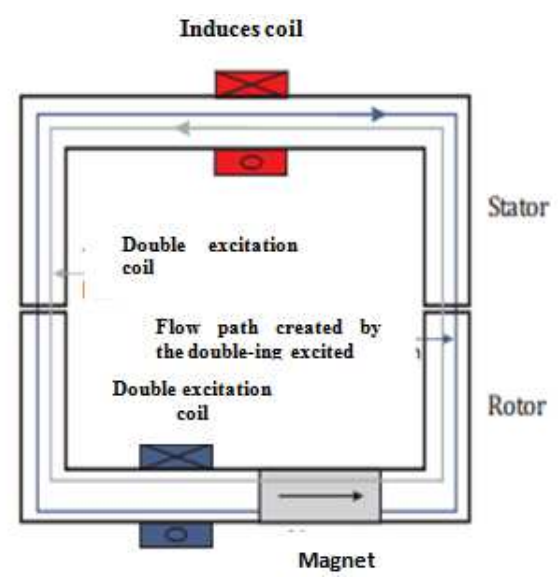

Figure 2. Serial double excitation synchronous machine.

The disadvantage of this type is that the double excitation coils are magnetically in series with the magnets. These have permeability close to that of air; the coils are therefore a high magnetic reluctance, which greatly reduces the efficiency of weakening by the coils.

An appropriate choice of the permanent magnet used is paramount to avoid the problem of irreversible demagnetization. The Iron Neodymium magnets Bor are generally recommended for this type of applications.

\section{Stator Sizing of the all Configurations}

All structures have the same motor stator. They therefore have the same dimensions.

The slot width of these structures is given by the following relationship [9]:

$$
\mathrm{L}_{\mathrm{enc}}=\left(\frac{\mathrm{D}_{\mathrm{e}}+\mathrm{D}_{\mathrm{i}}}{2}\right) \times \sin \left(\frac{1}{2} \times\left(\frac{2 \times \pi}{\mathrm{N}_{\mathrm{d}}}-\alpha \times \beta \times \frac{\pi}{\mathrm{p}} \times\left(1-\mathrm{r}_{\mathrm{did}}\right)\right)\right)
$$

Where $\mathrm{N}_{\mathrm{d}}$ is the number of main teeth and $\mathrm{r}_{\text {did }}$ is the report between angular width of an inserted tooth and a the angular width of main tooth.

For the configurations to trapezoidal shapes of waves, the height of a tooth is given by the following relation [9]:

$$
\mathrm{H}_{\mathrm{d}}=\frac{3 \times 2 \times \mathrm{N}_{\mathrm{s}}}{2 \times \mathrm{N}_{\mathrm{d}}} \times \frac{\mathrm{I}_{\mathrm{dim}}}{\delta} \times \frac{1}{\mathrm{~K}_{\mathrm{f}}} \times \frac{1}{\mathrm{~L}_{\mathrm{enc}}}
$$

For the configurations to sinusoïdal shapes of waves, the height of the teeth is expressed by the following relation [9]:

$$
\mathrm{H}_{\mathrm{d}}=\frac{3 \times 2 \times \mathrm{N}_{\mathrm{s}}}{2 \times \mathrm{N}_{\mathrm{d}}} \times \frac{\mathrm{I}_{\mathrm{dim}}}{\sqrt{2} \times \delta} \times \frac{1}{\mathrm{~K}_{\mathrm{f}}} \times \frac{1}{\mathrm{~L}_{\mathrm{enc}}}
$$

Where $\mathrm{K}_{\mathrm{f}}$ is the fill factor of slots, $\delta$ is the allowable current density in the slots and $\mathrm{I}_{\mathrm{dim}}$ is the dimensioning current of copper conductors.

This current is given by the following relationship:

$$
\mathrm{I}_{\mathrm{dim}}=\frac{\mathrm{C}_{\mathrm{dim}}}{\mathrm{K}_{\mathrm{e}}}
$$

Where $\mathrm{K}_{\mathrm{e}}$ is the back electromotive force constant.

\section{Determining of Electric Parameters of the Motor}

The study of the two-dimensional double-excitation synchronous machine is to etude conventional synchronous 
machine with permanent magnets. We study the influence of geometrical parameters on the machine performance (flux and electromagnetic torque load).

We will study here the influence of permanent magnets dimensions (height and width) and teeth static (width and height) on the maximum performance of the machine studied.

These effects will be evaluated analytically and by a $2 \mathrm{D}$ finite element method. To carry out this study, it is necessary to have an initial geometry. We will present the parametric study of the structure itself: it is to change the original structure so that it meets the specifications. This process has allowed us to scale a machine meets these specifications.

\subsection{Structures with Permanent Magnets}

The magnetic induction in the air gap is calculated for a position of maximum overlap (the edges of a magnet for MSAP configurations or the opening of the rotor coil for MSRB configurations, series excitation and those parallel excitation merge with the edges of the main tooth relative to the stator pole), since this position is relative to the maximum induction in the different active parts of the stator magnetic pole of the motor. The distribution of the field lines to this position is illustrated by figure 3 .

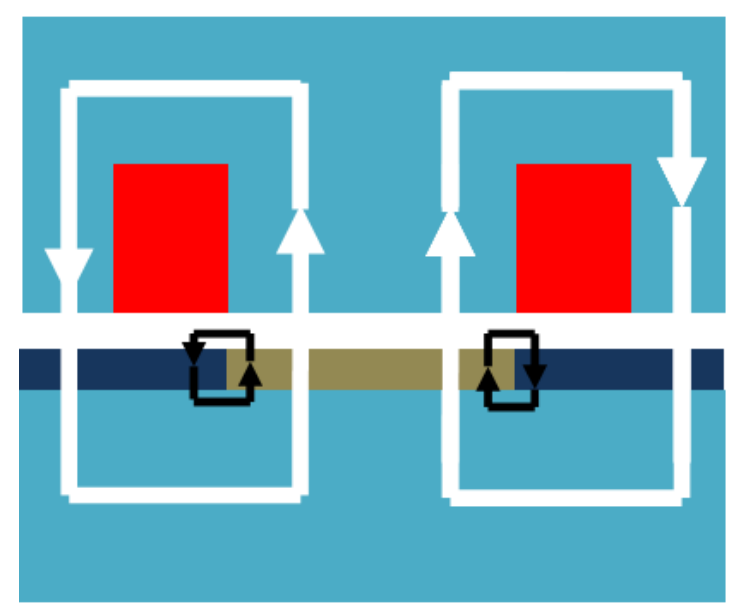

Figure 3. Distribution of the field lines to a position of maximum recovery.

This figure shows that the flux is divided into useful flux for the traction of the rotor and leakage flux between the magnets.

Applying Ampere's theorem at stator pole to a supply of the stator coil by the maximum current of the motor, regardless of the magnetic flux due to the magnets, used to calculate the magnetic induction caused by the current.

$$
\int \overrightarrow{\mathrm{H}} \times \overrightarrow{\mathrm{dl}}=\frac{\mathrm{N}_{s}}{\frac{\mathrm{N}_{\mathrm{d}}}{3}} \times \mathrm{I}_{\max }=2 \times\left(\mathrm{H}_{\mathrm{ri}} \times \mathrm{H}_{\mathrm{a}}+\mathrm{H}_{\mathrm{ri}} \times \mathrm{e}\right)
$$

Where $I_{\max }$ is the maximal current of the motor, $\mathrm{H}$ is the magnetic field, $\mathrm{H}_{\mathrm{ri}}$ is the magnetic field in the air-gap, $\mathrm{H}_{\mathrm{a}}$ is the height of a magnet, $e$ is the thickness of the air-gap, $\mu_{0}$ is the permeability of air, $N_{s}$ is the number of spires by phase and $N_{d}$ is the number of main teeth.

$$
\mathrm{B}_{\mathrm{ri}}=\mu_{0} \times \mathrm{H}_{\mathrm{ri}}
$$

Where $\mathrm{B}_{\mathrm{ri}}$ is the magnetic induction due to the energize of the motor by the maximal current $\left(\mathrm{I}_{\max }\right)$ :

$$
\mathrm{B}_{\mathrm{ri}}=\frac{\mu_{0}}{2 \times \frac{\mathrm{N}_{\mathrm{d}}}{3}} \times \frac{\mathrm{N}_{\mathrm{s}} \times \mathrm{I}_{\max }}{\mathrm{H}_{\mathrm{a}}+\mathrm{e}}
$$

This induction is negligible compared to the induction created by the magnets, since the flux generated by the coil through two times the thickness of the magnets and the air gap having both a very low magnetic permeability. Accordingly, only the magnetic flux generated by the magnets is used for sizing the motor.

This induction is derived from the application of Ampere law on a closed contour of the field lines:

$$
\int_{\text {Filed lines }} \overrightarrow{\mathrm{H}} \times \overrightarrow{\mathrm{dl}}=0=2 \times\left(\mathrm{H}_{\mathrm{m}} \times \mathrm{H}_{\mathrm{a}}+\mathrm{H}_{\mathrm{e}} \times \mathrm{e}\right)
$$

The magnetic induction in the air gap is linear in function of the magnetic field in the gap:

$$
\mathrm{B}_{\mathrm{e}}=\mu_{0} \times \mathrm{H}_{\mathrm{e}}
$$

While applying the theorem of conservation of flux to the level of the air-gap, we deducts the expression of the induction in the entrefer according to the induction in the magnets and the coefficient of leakage flux:

$$
\mathrm{B}_{\mathrm{a}} \times \mathrm{S}_{\mathrm{a}} \times \mathrm{K}_{\mathrm{fu}}=\mathrm{B}_{\mathrm{e}} \times \mathrm{S}_{\mathrm{d}}
$$

The magnetic induction of the magnets takes the following relation:

$$
\mathrm{B}_{\mathrm{a}}=\frac{\mathrm{S}_{\mathrm{d}}}{\mathrm{S}_{\mathrm{a}}} \times \frac{\mathrm{B}_{\mathrm{e}}}{\mathrm{K}_{\mathrm{fu}}}
$$

The induction in the magnets is approached by the following linear equation:

$$
\mathrm{B}_{\mathrm{a}}=\mu_{0} \times \mu_{\mathrm{r}} \times \mathrm{H}_{\mathrm{m}}+\mathrm{B}_{\mathrm{r}}
$$

Where $\mu_{\mathrm{r}}$ is the relative permeability of the magnets and $\mathrm{B}_{\mathrm{r}}$ is the residual magnetic induction of magnets.

From the equations (8), (9), (10), (11) and (12), we deducts the height of the magnets imposing an induction in the air-gap $\mathrm{B}_{\mathrm{e}}$. This induction is chosen of a manner to have magnetic inductions in the different active parts of the motor near of the bends saturation of the characteristic B-H, leading to a minimal mass of the motor and a working in the linear regime [9]:

$$
\mathrm{H}_{\mathrm{a}}=\mu_{\mathrm{r}} \times \frac{\mathrm{B}_{\mathrm{e}}}{\mathrm{B}_{\mathrm{r}}-\frac{\mathrm{S}_{\mathrm{d}} \times \mathrm{B}_{\mathrm{e}}}{\mathrm{S}_{\mathrm{a}} \times \mathrm{K}_{\mathrm{fu}}}} \times \mathrm{e}
$$

Where $\mathrm{K}_{\mathrm{fu}}$ is the leakages flux coefficient. 
To avoid the demagnetization of the magnets, the current of phase must be lower than demagnetization current $I_{d}[9]$ :

$$
I_{d}=\left(\frac{B_{r}-B_{c}}{\mu_{r}} \times H_{a}-B_{c} \times K_{f u} \times e\right) \times \frac{p}{2 \times \mu_{0} \times N_{s}}
$$

Where $B_{c}$ is the demagnetization induction, $B_{r}$ is the residual induction of magnets and $\mu_{0}$ is the permeability of air.

The height of the rotor yoke and the stator yoke is derived by application of the theorem of conservation of flux between the magnet and a rotor yoke, and between the stator tooth and the stator yoke [9]:

$$
\begin{aligned}
& \mathrm{H}_{\mathrm{cr}}=\frac{\mathrm{B}_{\mathrm{e}}}{\mathrm{B}_{\mathrm{cr}}} \times \frac{\operatorname{Min}\left(\mathrm{S}_{\mathrm{d}}, \mathrm{S}_{\mathrm{a}}\right)}{2 \times\left(\frac{\mathrm{D}_{\mathrm{e}}-\mathrm{D}_{\mathrm{i}}}{2}\right)} \times \frac{1}{\mathrm{~K}_{\mathrm{fu}}} \\
& \mathrm{H}_{\mathrm{cs}}=\frac{\mathrm{B}_{\mathrm{e}}}{\mathrm{B}_{\mathrm{cs}}} \times \frac{\operatorname{Min}\left(\mathrm{S}_{\mathrm{d}}, \mathrm{S}_{\mathrm{a}}\right)}{2 \times\left(\frac{\mathrm{D}_{\mathrm{e}}-\mathrm{D}_{\mathrm{i}}}{2}\right)}
\end{aligned}
$$

Where $\mathrm{B}_{\mathrm{cr}}$ and $\mathrm{B}_{\mathrm{cs}}$ are respectively the induction in the rotor yoke and in the stator yoke, $S_{d}$ and $S_{a}$ are respectively the section of a tooth and the one of a magnet and $\mathrm{K}_{\mathrm{fu}}$ is the coefficient leakages flux.

\subsection{Structures with Coiled Rotor}

The distribution of the field lines at a stator pole is shown in figure 4:

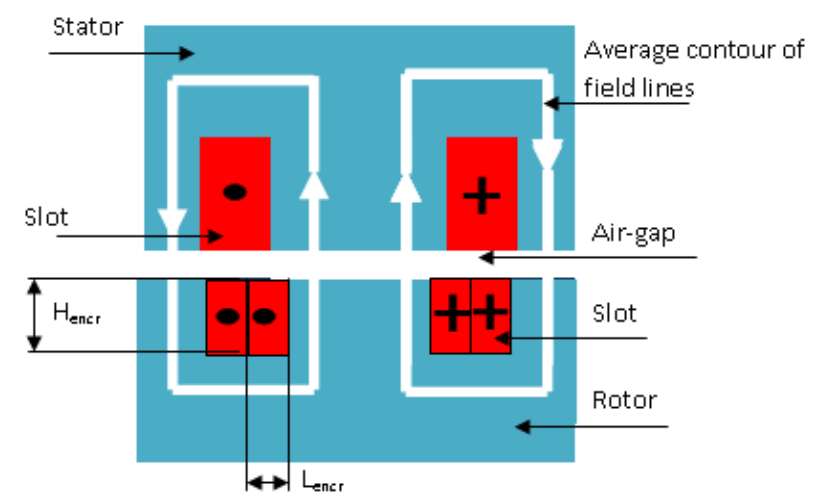

Figure 4. Distribution of the field lines to a position of maximum recovery.

The magnetic induction in the air gap is derived from the application of Ampere law on a closed contour of field lines:

$$
\int_{\text {Filed lines }} \overrightarrow{\mathrm{H}} \times \overrightarrow{\mathrm{dl}}=2 \times \mathrm{N}_{\mathrm{sr}} \times \mathrm{I}_{\mathrm{e}}=2 \times \mathrm{e} \times \mathrm{H}_{\mathrm{e}}
$$

The magnetic induction in the air gap is linear as a function of magnetic field:

$$
\mathrm{B}_{\mathrm{e}}=\mu_{0} \times \mathrm{H}_{\mathrm{e}}
$$

We deduce from relationships (17) and (18), expression of the induction in the air gap:

$$
\mathrm{B}_{\mathrm{e}}=\mu_{0} \times \frac{\mathrm{N}_{\mathrm{sr}}}{\mathrm{e}} \times \mathrm{I}_{\mathrm{e}}
$$

The width of a rotor slot depend on the factor of shortening of the main tooth $\gamma$ in relation to the polar step. In general, this coefficient doesn't pass $20 \%$ of the opening of the polar step:

$$
\mathrm{L}_{\text {encr }}=\frac{\mathrm{D}_{\mathrm{e}}-\mathrm{D}_{\mathrm{i}}}{4} \times \beta \times \frac{\pi}{\mathrm{p}} \times \gamma
$$

The height of the rotor slots depends on the density of the current allowable in the copper $\delta$ and the fill factor of slot $\mathrm{K}_{\mathrm{rr}}$.

$$
\mathrm{H}_{\mathrm{envr}}=\frac{\mathrm{e} \times \mathrm{B}_{\mathrm{e}}}{\mu_{0} \times \mathrm{K}_{\mathrm{rr}} \times \delta \times \mathrm{L}_{\mathrm{encr}}}
$$

\subsection{Structures with Serial Excitation}

The distribution of the field lines to the level of a stator pole is illustrated by figure 5 .

The induction in the air gap generated by the magnet is derived by application of Ampere law on a closed contour of the field lines and the theorem of conservation of the flux between a magnet and a main tooth:

$$
\mathrm{B}_{\mathrm{ea}}=\frac{\mathrm{H}_{\mathrm{a}} \times \mathrm{B}_{\mathrm{r}}}{\left(\frac{\mathrm{H}_{\mathrm{a}} \times \mathrm{S}_{\mathrm{d}}}{\mathrm{S}_{\mathrm{a}} \times \mathrm{K}_{\mathrm{fu}}}+\mu_{\mathrm{r}} \times \mathrm{e}\right)}
$$

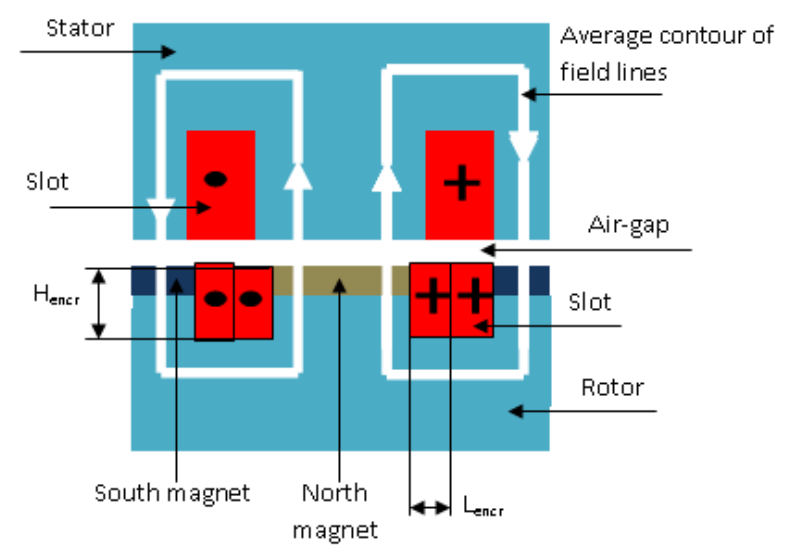

Figure 5. Distribution of the field lines to a position of maximum recovery.

The induction in the air-gap generated by the excitation of the motor by a current $I_{e}$ is deducted by application of the ampere theorem on a middle contour of the field lines:

$$
\mathrm{B}_{\mathrm{ee}}=\mu_{0} \times \frac{\mathrm{N}_{\mathrm{sr}} \times \mathrm{I}_{\mathrm{e}}}{\mathrm{H}_{\mathrm{a}}+\mathrm{e}}
$$

The application of the superposition field theorem in the air gap leads to the following expression for the induction in the air gap:

$$
\mathrm{B}_{\mathrm{e}}=\frac{\mathrm{H}_{\mathrm{a}} \times \mathrm{B}_{\mathrm{r}}}{\left(\frac{\mathrm{H}_{\mathrm{a}} \times \mathrm{S}_{\mathrm{d}}}{\mathrm{S}_{\mathrm{a}} \times \mathrm{K}_{\mathrm{fu}}}+\mu_{\mathrm{r}} \times \mathrm{e}\right)}+\mu_{0} \times \frac{\mathrm{N}_{\mathrm{sr}} \times \mathrm{I}_{\mathrm{e}}}{\mathrm{H}_{\mathrm{a}}+\mathrm{e}}
$$


The height of the magnets is calculated iteratively from this equation, of a manner to have a magnetic induction $B_{e}$ in the air-gap minimizing the mass of the motor (Inductions in the different active parts of the motor close to the elbow of saturation of the B-H curves) and guaranteeing a working in a linear régime.

The width of a rotor slot depend on the factor of shortening of the main tooth $\gamma$ in relation to the polar step. In general this coefficient doesn't pass $20 \%$ of the opening of the polar step:

$$
\mathrm{L}_{\text {encr }}=\frac{\mathrm{D}_{\mathrm{e}}-\mathrm{D}_{\mathrm{i}}}{4} \times \beta \times \frac{\pi}{\mathrm{p}} \times \gamma
$$

The height of the rotor slot depend on the density of the admissible current in the copper $\delta$ and the slot filling factor $\mathrm{K}_{\mathrm{rr}}$.

$$
\mathrm{H}_{\mathrm{encr}}=\frac{\mathrm{e} \times \mathrm{B}_{\mathrm{e}}}{\mu_{0} \times \mathrm{K}_{\mathrm{rr}} \times \delta \times \mathrm{L}_{\mathrm{encr}}}
$$

\subsection{Structures with Parallel Excitation}

The distribution of the field lines to the level of a stator pole is illustrated by the figure 6 .

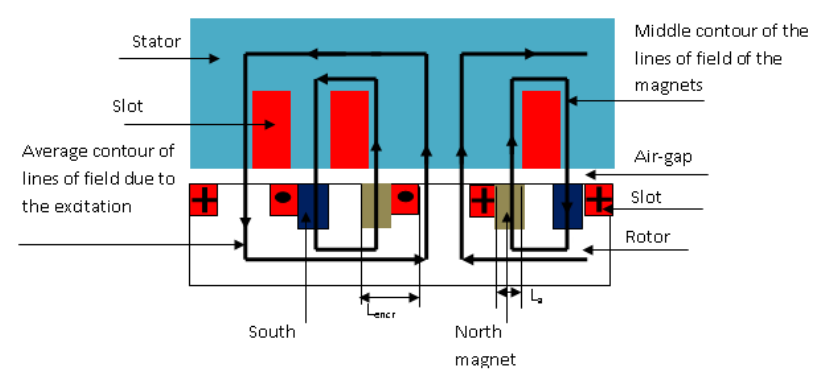

Figure 6. Distribution of the field lines to a position of maximum recovery.

The induction in the air gap generated by the magnet is derived by application of Ampere law on a closed contour of the field lines and the theorem of conservation of the flux between a magnet and a main tooth:

$$
\mathrm{B}_{\mathrm{ea}}=\frac{\mathrm{H}_{\mathrm{a}} \times \mathrm{B}_{\mathrm{r}}}{\left(\frac{\mathrm{H}_{\mathrm{a}} \times 2 \times \mathrm{S}_{\mathrm{d}}}{\mathrm{S}_{\mathrm{a}}}+\mu_{\mathrm{r}} \times \mathrm{e}\right)}
$$

The induction in the air gap generated by the motor by an excitation current $\mathrm{I}_{\mathrm{e}}$ is derived by application of Ampere's law on an average contour of the field lines:

$$
\mathrm{B}_{\mathrm{ee}}=\mu_{0} \times \frac{\mathrm{N}_{\mathrm{sr}} \times \mathrm{I}_{\mathrm{e}}}{\mathrm{e}}
$$

This induction corresponds to the maximal induction in the air-gap.

The height of the magnets is calculated iteratively from the equation (31), of a manner to have a magnetic induction in the air-gap $B_{\mathrm{e}}$ minimizing the mass of the motor (Inductions in the different active parts of the motor near of the elbow of saturation of the B-H curves) and guaranteeing a working in a linear régime.

The width of a rotor slot depend on the collar shortening factor of the main tooth $\gamma_{\mathrm{c}}$, doesn't pass $50 \%$ of the opening of the polar step in general:

$$
\mathrm{L}_{\mathrm{encr}}=\frac{\mathrm{D}_{\mathrm{e}}-\mathrm{D}_{\mathrm{i}}}{4} \times \beta \times \frac{\pi}{\mathrm{p}} \times \gamma_{\mathrm{c}}
$$

The height of the rotor slots depends on the density of the current allowable in the copper $\delta$ and the fill factor of slot $\mathrm{K}_{\mathrm{rr}}$ :

$$
\mathrm{H}_{\mathrm{encr}}=\frac{\mathrm{e} \times \mathrm{B}_{\mathrm{e}}}{\mu_{0} \times \mathrm{K}_{\mathrm{rr}} \times \delta \times\left(\mathrm{L}_{\mathrm{encr}}-\mathrm{L}_{\mathrm{a}}\right)}
$$

\subsection{Choice of Structure that Better Meets to Our Specifications}

To refine the choice of best structure suited to the specifications we have taken as a criterion for performance comparison. And after a review of the literature [4, 8, 9] depth on the subject, it seemed that the permanent magnet synchronous machine is the best choice.

Finally, after a comparative study on these structures we opted for the double excitation synchronous machine series "MSDE" because of its good performance compared to the machines of the same type and for the power density, congestion the cost of reduced production and have a simple excitation coil (figure 7)

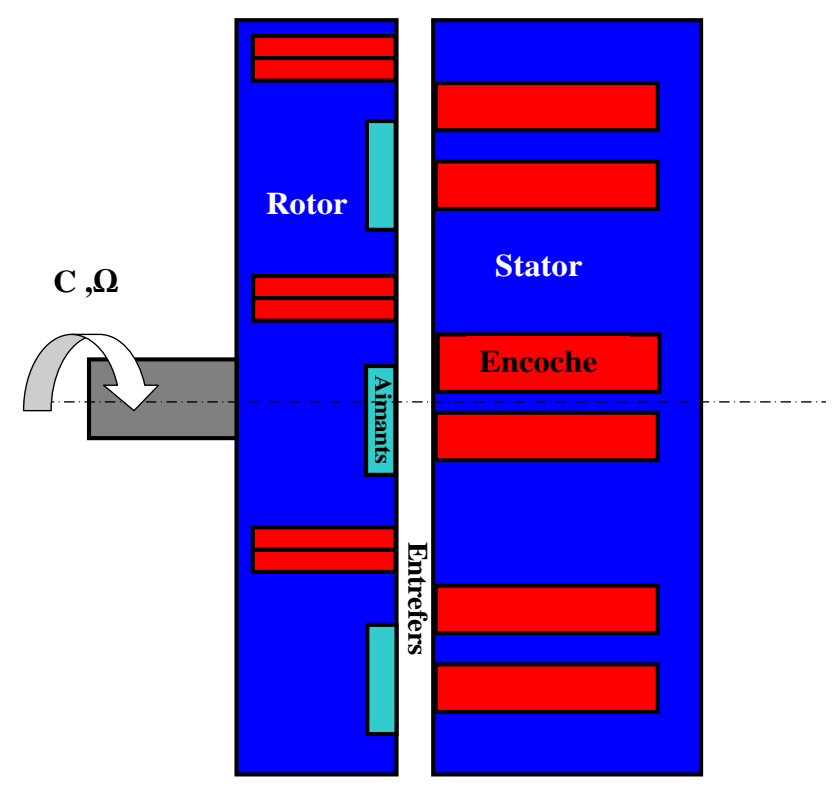

Figure 7. Synchronies' machine excitation double.

\section{Validation of the Model}

\subsection{Distribution of Field Line}

The distribution of field lines to load and load is shown in Figures 8 and 9: 


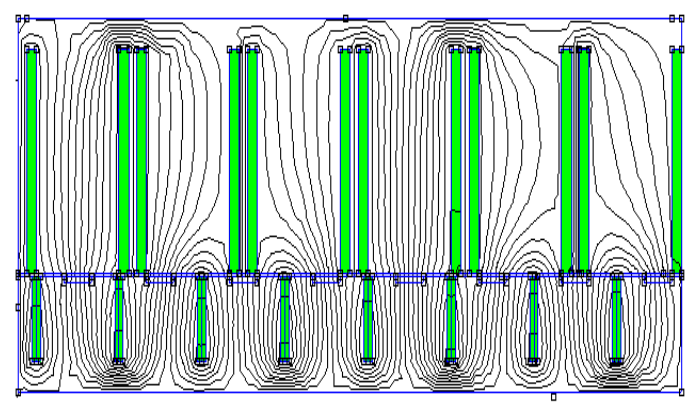

Figure 8. Field lines of the motor at no load.

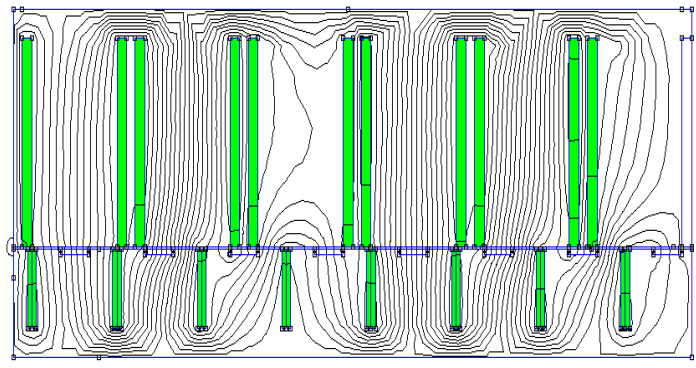

Figure 9. Field lines of the motor at load.

\subsection{Flux}

The figure 10 and 11 illustrate the trend of the flow of three phases to empty and loaded according to $\theta$.

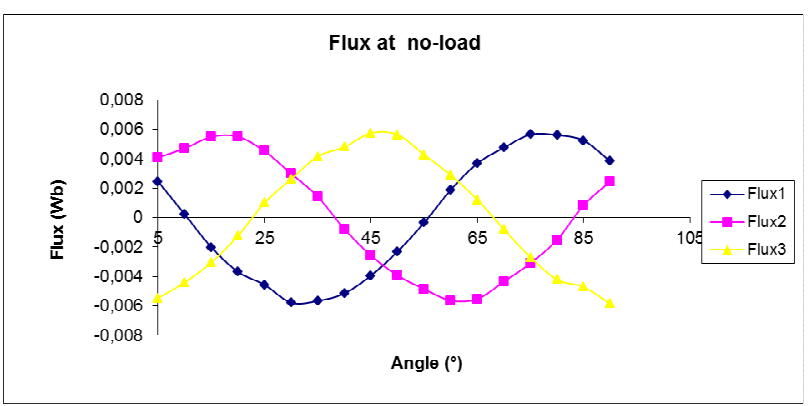

Figure 10. Flux at no-load.

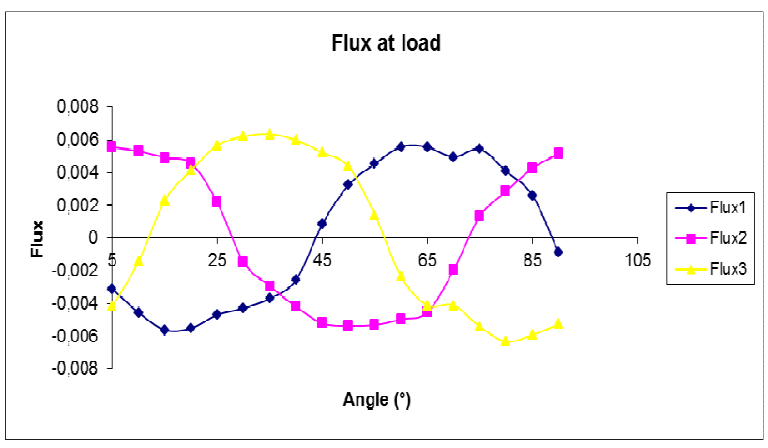

Figure 11. Flux at load.

We note from figures 13 and 14 that the flow undergoes a slight deformation load. This is due to the magnetic armature reaction. The flow reaches the value calculated analytically, which validates the analytical design approach.

\subsection{Electromotive Forces Against}

The figure 12 and 13 show the results obtained from the back M.F.E:

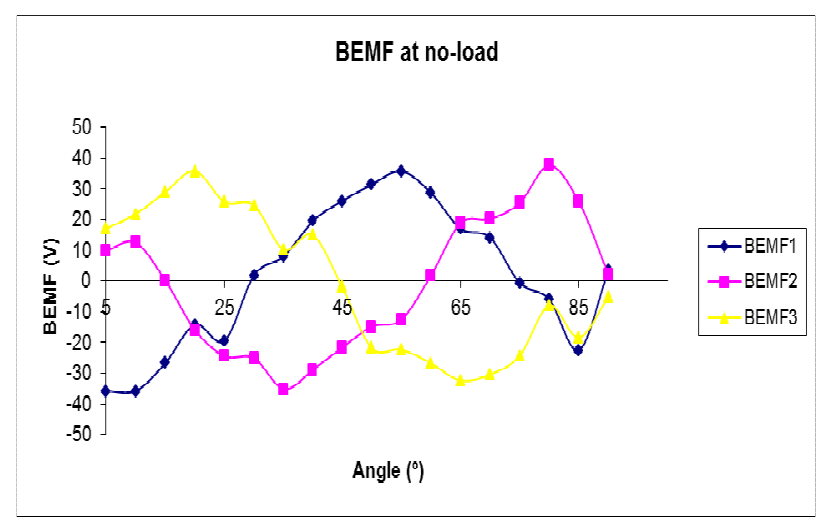

Figure 12. Back M.F.E.at no-load.

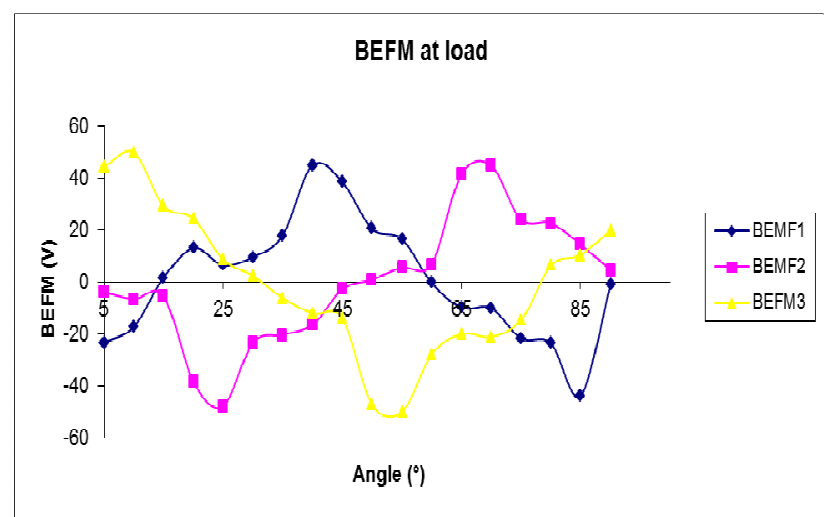

Figure 13. Back M.F.E.at load.

\subsection{Electromagnetic Torque}

The figure 14 illustrates the torque variation of motor according to the swing angle at load and at no load.

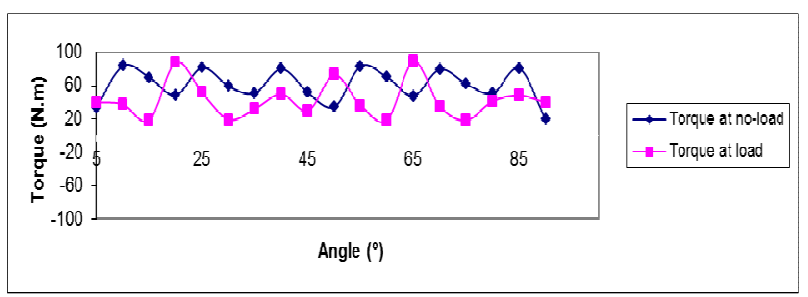

Figure 14. Load torque and load.

The torque ripple is mainly due to the presence of cogging torque

\section{Conclusion}

In this article, we presented a method for calculating the parameters of a synchronous dual actuator excitation by finite element method.

The results validate the analytical model. Indeed, in a first step, we determined the analytical values of flux, electromotive force against the torque calculated by the finite element simulations; in a second step we validate the model by 
finite element simulations.

This work will allow us to develop to allow control and optimization studies for these types of engines.

\section{References}

[1] M. HADJ KACEM, " Conception des Composants Electriques de la Chaîne de Puissance d'un Véhicule Electrique"; Thèse de Doctorat 2013. ENIS Tunisie.

[2] S. TOUNSI, M. HADJ KACEM et R. NEJI « Design of Static Converter for Electric Trac-tion », International Review on Modelling and Similations (IREMOS) Volume 3, N. 6, De-cember 2010, pp. 1189-1195.

[3] M.HADJ KACEM, S.TOUNSI et R. NEJI: « Systemic Design and Control of Electric Vehicles Power Chain »; IJSTR, volume1, $\mathrm{n}^{\circ}$ 2012,pp.73-81.

[4] S.TOUNSI, R.NÉJI, F.SELLAMI: Design of a Permanent Magnet Actuator for Electric Vehicles. Revue Internationale de Génie Électrique volume 9/6 2006 - pp.693-718.
[5] Y. Amara, J. Lucidarme, M. Gabsi : A new topology of hybrid synchronous machine. IEEE Trans.Ind.Appl., vol .37, Issue 5, pp. 1273-1281.

[6] S. TOUNSI, N. BEN HADJ, R. NEJI et F. SELLAMI, "Optimization of Electric Motor Design Parameters Maximizing the autonomy of electric vehicles", International Review of Electrical Engineering (IREE), ISSN 1827-6660, Volume $2 \mathrm{~N}^{\circ}$ 1, January-February 2007, pp.118-126. .

[7] Y. Amara : «Contribution à la conception et à la commande des machines synchrones à double excitation. Application au véhicule hybride », Thèse de Doctorat, Université de Paris, 2001.

[8] S.TOUNSI: «Conception et Optimisation Systématiques de la Chaîne de Puissance des Véhicules Electriques»; Habilitation universitaire, Ecole Nationale d'Ingénieurs de Sfax - Tunisie, Mai 2012.

[9] D. FODOREAN: Design and implementation of a synchronous machine double excitation: Application to the direct drive: Doctoral thesis, 2005. 